\title{
Estudo da viabilidade de utilização do Resíduo de Borracha de Pneu em Concretos Estruturais
}

Study the feasibility of using Tire Rubber Residue in Structural Concrete

Estudio de viabilidad del uso de Neumáticos Fuera de Uso para Hormigones

Estructurales

João Victor Fazzan

Aluno de doutorado do PPGCM, UNESP - FEIS, Brasil Professor Adjunto, IFSP - Câmpus Avançado Ilha Solteira/SP, Brasil. jvfazzan@hotmail.com

Adriana Maria Pereira Aluna de doutorado do PPGCM, UNESP - FEIS, Brasil Professora Auxiliar, IFSP - Câmpus Presidente Epitácio/SP, Brasil. adrianapereiradu@gmail.com

Jorge Luís Akasaki Professor Adjunto, UNESP - FEIS, Brasil jorge.akasaki@gmail.com 


\section{RESUMO}

Atualmente, diversas pesquisas têm sido feitas no sentido de ampliar as possibilidades de uso do concreto mediante o emprego de outros materiais em sua constituição, que, por sua vez, lhe proporcione novas propriedades. Dentre os materiais alternativos, a borracha reciclada de pneu inservível apresenta propriedades técnicas que podem ser interessantes para seu uso em aplicação como agregado ao concreto. Aliado à sua degradação lenta, o descarte inadequado dos pneus inservíveis em aterros sanitários tem acarretado prejuízos à natureza, e, para que o mercado de pneus se torne sustentável, é necessário um esforço conjunto das partes envolvidas na coleta, armazenamento e reciclagem, aliando políticas e programas governamentais com o desenvolvimento de tecnologias inovadoras. Sendo assim, o objetivo do trabalho foi analisar a possibilidade de se utilizar fibras de borracha de pneu na produção de concretos estruturais, avaliando-se as propriedades de Resistência à Compressão Axial, Resistência à Tração por Compressão Diametral, Módulo de Elasticidade, Absorção de Água, Massa Específica e Teor de Ar Incorporado. O estudo inicial da pesquisa partiu da elaboração dos traços de concreto, para a substituição de $10 \%$ de resíduo de borracha em relação ao volume de agregado miúdo. De acordo com os resultados obtidos, os métodos de dosagem empregados se mostraram eficientes na obtenção da resistência mínima requerida para os traços sem e com adição de resíduo, mostrando um ganho das propriedades mecânicas para as misturas constituídas de borracha. Evidencia-se, portanto, a viabilidade de utilização dos resíduos de borracha de pneu na elaboração de concretos estruturais.

PALAVRAS-CHAVE: Resíduo de Borracha de Pneu. Concretos Estruturais. Propriedades Mecânicas.

\section{ABSTRACT}

Currently, several studies have been made to expand the use of concrete possibilities through the use of other materials in its constitution, which, in turn, provide new properties. Among the alternative materials, tire rubber residues has technical properties that can be interesting for use in application and added to the concrete. With its slow degradation, improper disposal of scrap tires in landfills has caused damage to nature, and so that the tire market becomes sustainable, an effort is necessary to all parties involved in the collection, storage and recycling, combining policies and government programs with the development of innovative technologies. Thus, the objective of this study was to analyze the possibility of using tire rubber residues in the production of structural concrete, evaluating the properties of Compressive Strength, Tensile Strength, Modulus of Elasticity, Water Absorption Content, Unit Weight and Entrained-Air Content. The initial research study came from the preparation of concrete mixtures, to replace $10 \%$ of rubber residue on the volume of fine aggregate. According to the results obtained, the dosage methods were effective for obtaining the minimum strength required for the mixtures with and without addition residue, showing a gain in mechanical properties to the rubber mixtures. Is evident therefore, the feasibility of using tire rubber residue in the preparation of structural concrete.

KEY-WORDS: Tire Rubber Residues. Strctural Concretes. Mechanical properties.

\section{RESUMEN}

En la actualidad, se han realizado varios estudios para ampliar las posibilidades del uso de hormigones mediante el uso de otros materiales en su constitución, la cual, a su vez, le proporcionan nuevas propiedades. Entre los materiales alternativos, caucho reciclado de neumáticos de desecho tiene propiedades técnicas que pueden ser interesantes para su uso en la aplicación y se agrega al concreto. Junto con su lenta degradación, la eliminación inadecuada de las llantas de desecho en vertederos ha causado daños a la naturaleza, y para que el mercado de los neumáticos sea sostenible, un esfuerzo es necesario para todas las partes involucradas en la recogida, almacenamiento y reciclaje, envolvendo la combinación de políticas y programas de gobierno con el desarrollo de tecnologías innovadoras. Por lo tanto, el objetivo de este estudio fue analizar la posibilidad de utilizar neumáticos fuera de uso en la producción de hormigón estructural, para evaluar las propiedades de resistencia a la compresión axial, resistencia a la tracción por compresión diametral, módulo de elasticidad, absorción de agua, densidad y contenido de aire incorporado. El estudio inicial de investigación provino de la preparación de mezclas de hormigón, para reemplazar el $10 \%$ de neumáticos fuera de uso en el volumen de agregado fino. De acuerdo con los resultados obtenidos, los métodos de dosificación usados fueron eficaces para la obtención de la fuerza mínima necesaria para las mezclas con y sin residuo. Además, muestra un aumento de las propiedades mecánicas para las mezclas com neumáticos fuera de uso. Es evidente, por lo tanto, la viabilidad de la utilización de residuos de caucho de los neumáticos en la preparación de hormigón estructural.

PALABRAS CLAVE: Neumáticos fuera de uso. Hormigones Estructurales. Propiedades mecánicas. 


\section{INTRODUÇÃO}

Um dos vários problemas que a humanidade vem enfrentando no início do século XXI é a dificuldade da destinação correta dos resíduos. Grandes quantidades de pneus de aviões, de caminhões e de carros são descartadas quando os mesmos se tornam inservíveis, ou seja, quando não têm mais condições de serem reformados (ADHIKARI et al. apud KAMIMURA, 2002).

De fato, o aumento do acúmulo de pneus inservíveis está diretamente relacionado com a fragilidade da legislação e a falta de incentivo à reciclagem, o que tem conduzido às crises dos aterros sanitários e aos problemas de saúde pública.

Em função da produção em grande escala dos pneumáticos, tem-se constatado que seu descarte vem aumentando a cada ano. De fato, segundo a Associação Nacional da Indústria de Pneumáticos - ANIP (2016), em 2015, foram produzidos no Brasil 68,6 milhões de unidades de pneu. A Reciclanip, entidade que é parte do Sistema ANIP, coletou e destinou de forma ambientalmente correta mais de 114,5 mil toneladas de pneus inservíveis durante o primeiro trimestre deste ano. Esta quantia equivale a 22,9 milhões de unidades de pneus de carros de passeio retirados das ruas, estradas e rios das 27 capitais brasileiras.

Sendo assim, a incorporação de resíduos em misturas concreto surge como uma possibilidade para se atenuar impactos ambientais. De fato, uma grande quantidade de pesquisas tem indicado o uso potencial dos materiais cimentícios com adição de resíduo de borracha de pneu em aplicações sem função estrutural. Entretanto, pouco se tem estudado sobre materiais à base de cimento com adição de resíduos em elementos estruturais, em função do efeito negativo na redução da capacidade de carga compressiva em amostras com resíduo (HOLMES, DUNNE E O'DONNELL, 2014). Sendo o material concreto um elemento frágil, com alta rigidez, e a borracha de pneu um material altamente elástico, é de grande importância que se estude o comportamento dos dois materiais quando estes estiverem trabalhando juntos.

Ao mesmo tempo, atualmente no Brasil tem-se dado atenção quanto aos programas de habitação popular, em função do grande déficit habitacional que o país possui. Portanto, existe a possibilidade de se aumentar a velocidade da construção de unidades habitacionais, sem, no entanto, gerar prejuízos ao ambiente, fazendo uso de materiais de construção ecologicamente corretos.

A maioria das pesquisas tem demonstrado que o concreto com adição de borracha possui resistência mecânica inferior ao concreto convencional. Siddique e Naik (2004) mencionam que tal efeito pode ser atribuído à baixa aderência entre a borracha e a matriz de cimento. Por outro lado, segundo Marques et al. (2005) e Lopes et al. (2005), para manter a resistência constante com a adição do elastômero, é necessário aumentar o consumo de cimento, ou seja, diminuir o fator água/cimento.

Son, Hajirasouliha e Pilakoutas (2011) analisaram a deformabilidade e a capacidade de absorção de energia em pilares de concreto armado constituídos de resíduo de borracha de pneu. Os concretos foram elaborados utilizando-se dois diferentes tamanhos de partículas de borracha de pneus $(0,6 \mathrm{~mm}$ e $1 \mathrm{~mm})$, nas proporções de $0,5 \%$ e $1 \%$ de borracha em relação ao peso total de agregados (correspondente a $2,7 \%$ e $5,4 \%$ em volume, respectivamente), para se 
produzir concretos com resistências à compressão de 24 e $28 \mathrm{MPa}$. Na análise dos concretos, foram verificadas reduções de $12 \%$ a $22 \%$ da resistência à compressão para os traços com resíduo, em relação aos traços convencionais. Os resultados também mostraram reduções de 10 a 15\% nos valores de módulo de elasticidade dos concretos com borracha.

Aliado às reduções do módulo de elasticidade de concretos com resíduo de pneu, Holmes, Dunne e O'Donnell (2014) obtiveram um aumento significativo nos valores de resistência à flexão de vigas com adição de resíduos de borracha de pneu. Tal comportamento se mostrou favorável a um tipo de ruptura com maior ductilidade, que proporcionou um aumento da capacidade de absorção de energia.

\section{OBJETIVOS}

\subsection{OBJETIVO GERAL}

- O objetivo geral do trabalho foi analisar a possibilidade de se utilizar fibras de borracha de pneu na produção concretos estruturais.

\subsection{OBJETIVOS ESPECÍ́FICOS}

- -Estudar um método de dosagem dos materiais, visando obter, para as amostras sem e com resíduo de borracha de pneu, resistências à compressão próximas, sem um aumento significativo do consumo de cimento decorrente da inclusão do resíduo de borracha no concreto.

- Analisar as propriedades mecânicas e físicas dos corpos de prova de concreto produzidos com fibras de borracha de pneu e;

- Ponderar sobre a utilização de fibras de borracha de pneu, material abundantemente encontrado no Brasil e que não apresenta uma destinação adequada.

\section{METODOLOGIA}

\subsection{MATERIAIS UTILIZADOS}

\subsubsection{CIMENTO}

Nesta pesquisa, utilizou-se o cimento CP II Z 32 (Cimento Portland Composto de Pozolanas) para a elaboração dos corpos de prova, pelo fato de seu emprego ser em larga escala para obras residenciais. Além disso, trata-se do cimento comercialmente vendido na região noroeste do Estado de São Paulo.

Estes cimentos foram caracterizados tanto fisicamente quanto quimicamente, atendendo os requisitos especificados pela Associação Brasileira de Normas Técnicas (ABNT). O material apresentou Massa Específica Aparente de $1,09 \mathrm{~g} / \mathrm{cm}^{3}$ e Massa Específica Absoluta de 3,11 $\mathrm{g} / \mathrm{cm}^{3}$. 


\subsubsection{RESÍDUO DE BORRACHA DE PNEU E AGREGADOS}

Na fabricação dos concretos convencionais e com resíduo de borracha de pneu, utilizou-se, como agregado miúdo, a areia natural classificada como areia média. Como agregado graúdo, foram utilizadas britas de origem basáltica. Os resultados de caracterização dos agregados encontram-se na Tabela 1.

Os resíduos de borracha de pneu foram fornecidos por uma empresa recauchutadora de pneus, situada na cidade de Ilha Solteira - SP. Após o recebimento do material, impurezas como fios de nylon e fios de aço foram retirados.

Para a confecção dos concretos, foi selecionada uma faixa granulométrica do resíduo a ser utilizado por meio de um processo de peneiramento classificatório.

Deste modo, determinou-se um jogo de peneiras de modo a separar os resíduos de borracha em faixas granulométricas bem definidas, apresentando inclusive fácil distinção visual, conforme mostra o Quadro 1. A Figura 1 mostra os resíduos de borracha de pneu utilizados na pesquisa.

Os resultados de caracterização do resíduo de borracha e sua curva granulométrica encontramse na Tabela 1 e Figura 2, respectivamente. Destaca-se que foram incluídas na Figura 2, as curvas granulométricas da areia e brita.

Tabela 1 - Caracterização dos Agregados Miúdo e Graúdo e Resíduo de Borracha de Pneu

\begin{tabular}{cccccccc}
\hline & $\begin{array}{c}\varnothing \text { máx } \\
(\mathrm{mm})\end{array}$ & $\begin{array}{c}\text { Módulo } \\
\text { de } \\
\text { Finura }\end{array}$ & $\begin{array}{c}\text { Massa } \\
\text { Específica S.S.S } \\
\left(\mathrm{g} / \mathrm{cm}^{3}\right)\end{array}$ & $\begin{array}{c}\text { Massa Específica } \\
\text { Aparente } \\
\left(\mathrm{g} / \mathrm{cm}^{3}\right)\end{array}$ & $\begin{array}{c}\text { Absorção } \\
(\%)\end{array}$ & $\begin{array}{c}\text { Pulverulento } \\
(\%)\end{array}$ & $\begin{array}{c}\text { Matéria } \\
\text { Orgânica }\end{array}$ \\
\hline Miúdo & 2,36 & 2,03 & 2,600 & 1,492 & 0,34 & 0,48 & + clara \\
Graúdo & 19,0 & 6,91 & 2,929 & 1,595 & 1,22 & 0,36 & --- \\
Resíduo & 4,75 & 3,81 & 1,09 & 0,348 & --- & --- & --- \\
\hline
\end{tabular}

Fonte: ELABORADO PELOS AUTORES, 2016

Quadro 1 - Classificação granulométrica do Resíduo de Borracha de Pneu

\begin{tabular}{|c|c|c|c|c|}
\hline \multicolumn{5}{|c|}{ Classificação Granulométrica do Resíduo de Borracha de Pneu } \\
\hline \multicolumn{2}{|c|}{ Peneiras Normais e Auxiliares } & \multicolumn{4}{c|}{ Resíduo de borracha de pneu } \\
\hline Denominação da ABNT & Abertura (mm) & \% Retida & Denominação do Trabalho & Observação \\
\hline 1/4" & 6,3 & 1,7 & B. Muito Grossa & Não utilizada \\
\hline N.o 8 & 2,38 & 27,8 & Borracha Grossa & Utilizada \\
\hline N.o 16 & 1,19 & 32,8 & Borracha Média & Utilizada \\
\hline Fundo & 0,075 & 37,7 & Borracha Fina & Utilizada \\
\hline
\end{tabular}

Fonte: ELABORADO PELOS AUTORES, 2016

Figura 1 - Separação do resíduo em diferentes granulometrias

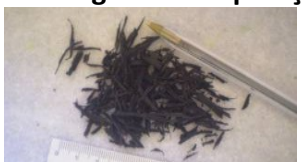

(a) Borracha Grossa

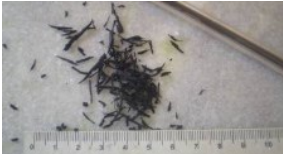

(b) Borracha Média

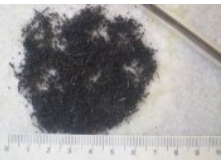

(c) Borracha Fina 
Figura 2 - Curva Granulométrica dos Agregados e Resíduo de Borracha

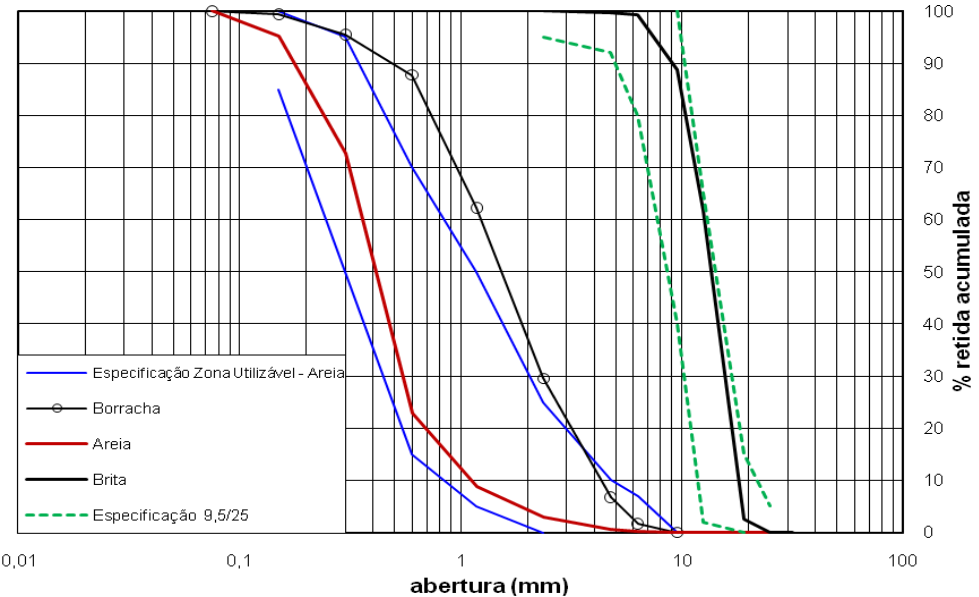

Fonte: ELABORADO PELOS AUTORES, 2016

\subsubsection{ADITIVO QUÍMICO E ÁGUA}

O aditivo químico utilizado na pesquisa foi um superplastificante à base de policarboxilato. Segundo dados fornecidos pelo fabricante, possui massa específica de 1,10Kg/l, para dosagens de $0,5 \%$ a $1,5 \%$ em relação ao peso de cimento. Além disso, utilizou-se água potável proveniente da rede de tratamento público da cidade de Ilha Solteira - SP.

\subsection{MÉTODO DE DOSAGEM DE CONCRETO}

A metodologia inicial para dosagem dos concretos sem adição de resíduos (Mistura Controle) foi elaborada por meio do método proposto de Helene e Terzian (1993), partindo do princípio que são necessários três pontos para se montar o diagrama de dosagem do método, conforme apresentado na Figura 3. O esquema abaixo correlaciona resistência à compressão (fcj), relação água /cimento $(\mathrm{a} / \mathrm{c})$, traço $(\mathrm{m})$ e consumo de cimento $(\mathrm{C})$.

Figura 3 - Diagrama de dosagem de concretos

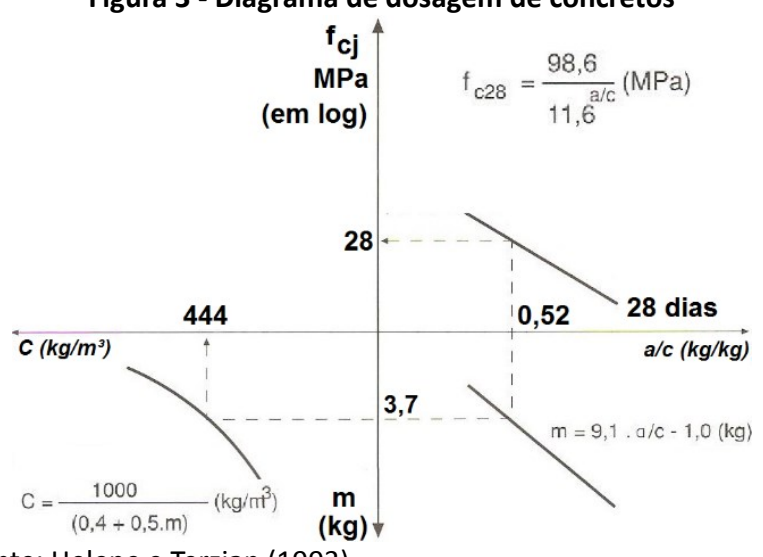

Fonte: Helene e Terzian (1993) 
O início do estudo experimental partiu da avaliação preliminar, com mistura em betoneira do traço 1:5 (cimento: agregados secos totais, em massa). Baseados nas informações obtidas desta mistura, confeccionam-se mais duas, com traços definidos em 1:3,5 (traço rico) e 1:6,5 (traço pobre), para possibilitar a montagem do diagrama de dosagem, que correlaciona resistência à compressão, relação água /cimento, traço e consumo de cimento. A partir da resistência à compressão desejada, obtém-se as características do traço definitivo.

Para os traços com adição de resíduo, procedeu-se com alguns ajustes dos traços controle; para isso, utilizou-se o método da Massa Compactada Unitária (MUCm) proposto por O’Reilly Díaz (1998) para a obtenção do teor de argamassa; a partir do teor de argamassa encontrado, foi feito um estudo relacionando a diminuição do consumo de cimento e o aumento da quantidade de superplastificante na mistura.

\subsection{ESTUDO DAS COMPOSIÇÕES DOS CONCRETOS}

Definiram-se para os concretos convencionais e com adição de borracha de pneu os seguintes parâmetros: Resistência à Compressão Axial, aos 28 dias de idade, acima de $25 \mathrm{MPa}$; fixação do abatimento em $7 \pm 1 \mathrm{~cm}$ para a mistura sem resíduo e $10 \pm 1 \mathrm{~cm}$ para as misturas com resíduo; teor de ar incorporado de $15 \mathrm{l} / \mathrm{m}^{3}$ e substituição de $10 \%$ de resíduo de borracha em relação ao volume de agregado miúdo.

Os traços finais de concreto foram atribuídos como:

- TC: Traço de concreto sem resíduo de borracha de pneu (Controle).

- TR: Traço de concreto com resíduo de borracha de pneu.

As composições dos concretos sem e com adição de resíduos estão definidas na Tabela 2.

\begin{tabular}{ccc} 
Tabela 2 - Composição final dos traços com adição de Resíduo de Borracha de Pneu \\
\hline Traço & TC & TR \\
\hline Materiais & \multicolumn{2}{c}{ Consumo $\left(\mathbf{K g} / \mathbf{m}^{\mathbf{3}}\right)$} \\
\hline Água & 192,0 & 140,0 \\
Cimento & 342,0 & 360,0 \\
Areia & 884,0 & 772,6 \\
Brita & 1003,0 & 1197,1 \\
Resíduo de Borracha & --- & 36,0 \\
\hline Relações & \multicolumn{3}{c}{ Índices } \\
\hline Relação (1:m) & 6,19 & 6,36 \\
Teor de Argamassa (\%) & 56,8 & 52,2 \\
Volume de Argamassa (\%) & 65,7 & 59,1 \\
Superplastificante (\% peso cimento) & --- & 0,810 \\
Água/Cimento (A/C) & 0,561 & 0,390 \\
\hline
\end{tabular}

Fonte: ELABORADO PELOS AUTORES, 2016

\subsection{PROCEDIMENTOS APLICADOS ÀS COMPOSIÇÕES DOS CONCRETOS}

\subsubsection{MISTURA}

Primeiramente, com a betoneira desligada, foram inseridos os agregados miúdos, graúdo e aproximadamente $50 \%$ da água de amassamento. Em seguida, a betoneira foi ligada por um 
minuto para a mistura dos materiais. Posteriormente, adicionou-se o cimento e o restante da água de amassamento, ligando-se a betoneira por mais três minutos, que foram seguidos de três minutos de descanso. Como etapa final, foram definidos os seguintes tempos para mistura:

- Concreto referência: ligou-se a betoneira por mais três minutos;

- Concreto com inserção de resíduo: acrescentou-se o aditivo superplastificante com a betoneira em movimento deixando-a ligada por mais 5 minutos. Em seguida, adicionou-se o resíduo de borracha, ligando-se a betoneira por mais 1 minuto.

\subsubsection{ENSAIOS}

Após a retirada do concreto da betoneira, foram realizados os ensaios: Abatimento do Tronco de Cone, seguindo as recomendações da NBRNM 67 (ASSOCIAÇÃO BRASILEIRA DE NORMAS TÉCNICAS - ABNT, 1998); moldagem dos corpos de prova em fôrmas cilíndricas de dimensões $10 \mathrm{~cm} \times 20 \mathrm{~cm}$, segundo a NBR 5738 (ASSOCIAÇÃO BRASILEIRA DE NORMAS TÉCNICAS - ABNT, 2008) e adensamento em mesa vibratória; determinação da Resistência à Compressão axial e Módulo de Elasticidade aos 7 e 28 dias de acordo com a NBR 5739 (ASSOCIAÇÃO BRASILEIRA DE NORMAS TÉCNICAS - ABNT, 2007) e NBR 8522 (ASSOCIAÇÃO BRASILEIRA DE NORMAS TÉCNICAS - ABNT, 2008), respectivamente, determinação da Resistência à Tração por compressão diametral, de acordo com a NBR 7222 (ASSOCIAÇÃO BRASILEIRA DE NORMAS TÉCNICAS - ABNT, 2007), determinação da absorção de água e massa específica, de acordo com a NBR 9778 (ASSOCIAÇÃO BRASILEIRA DE NORMAS TÉCNICAS - ABNT, 2009) e Teor de Ar Incorporado, preconizado pela NBRNM 47 (ASSOCIAÇÃO BRASILEIRA DE NORMAS TÉCNICAS ABNT, 2002).

Para cada ensaio, considerando cada traço, foram moldados três corpos de prova, tomando-se como resistência final a média aritmética das tensões e propriedades.

\section{RESULTADOS}

\subsection{MÉTODOS DE DOSAGEM}

O método IPT/EPUSP apresentado por Helene e Terzian (1993) foi aplicado nas composições dos traços sem adição de resíduo. Para isso, foi obtido através de tentativas, pelo método visual, um teor de argamassa ideal de $56,8 \%$, garantindo que a argamassa pudesse envolver adequadamente o agregado graúdo, tendo-se obtido um consumo de cimento de $342 \mathrm{Kg} / \mathrm{m}^{3}$ de concreto.

Considerando a redução nas resistências à compressão em função do incremento da borracha, decidiu-se por aumentar o consumo de cimento para $360 \mathrm{~kg} / \mathrm{m}^{3}$, utilizando aditivo superplastificante. Dessa forma, pode-se relatar um aumento no consumo de cimento de $5,3 \%$ para o concreto com resíduo, em relação ao consumo do traço controle.

A trabalhabilidade do concreto com adição de resíduos e superplastificante se mostrou adequada, sem perda de consistência durante o ensaio de Abatimento do Tronco de Cone e moldagem dos corpos de prova, além da ausência de segregação e exsudação. Para o ensaio do Abatimento do Tronco de Cone (Slump Test), obteve-se um valor de $8,0 \mathrm{~cm}$ para o traço 
controle e $11,0 \mathrm{~cm}$ para o traço com resíduo, estando dentro das especificações definidas nos procedimentos experimentais. Por se trabalhar com aditivos superplastificantes para os traços com resíduos, decidiu-se aumentar os valores de abatimento, favorecendo a trabalhabilidade dos traços quando se adiciona resíduo nas misturas (Figura 4).

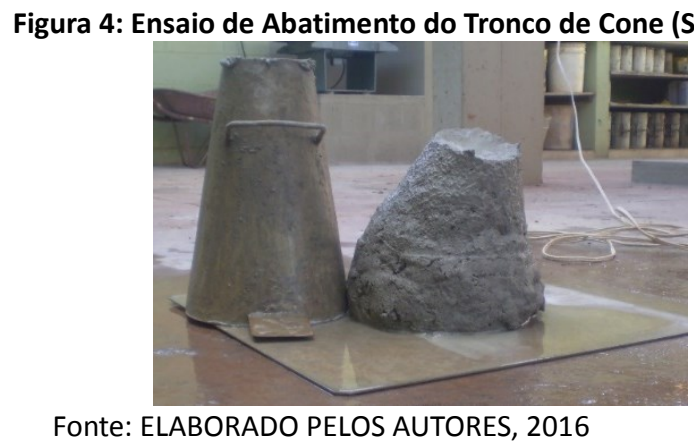

Os dados de Resistência à Compressão Axial, Resistência à Tração por Compressão Diametral e Módulo de Elasticidade foram calculados considerando o desvio relativo máximo, conforme item 3.6.3 da NBR 7215 (1997). Para desvios relativos máximos superiores a 6\%, foram desconsiderados os valores discrepantes e calculadas novas médias, conforme prescreve o item 3.6.4 da NBR 7215 (1997).

\subsection{RESISTÊNCIA À COMPRESSÃO AXIAL}

A Figura 5 abaixo mostra os resultados de Resistência à Compressão Axial dos Corpos de Prova controle e constituídos de resíduos de borracha de pneu, aos 7 e 28 dias de cura.

Figura 5: Resultados de Resistência à Compressão Axial dos corpos de prova com e sem resíduo de borracha de pneu aos 7 e 28 dias de cura

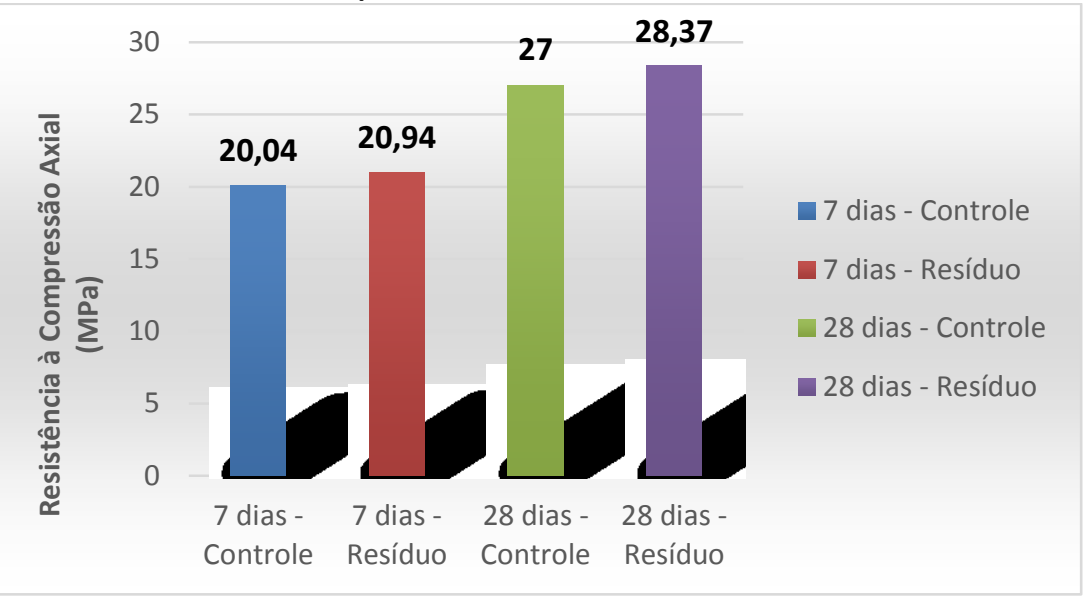

Fonte: ELABORADO PELOS AUTORES, 2016

Em se tratando de concreto armado estrutural, a NBR 6118 (ABNT, 2014) exige concreto com resistência mínima de $20 \mathrm{MPa}$ aos 28 dias de cura, quando trata de casos menos agressivos.

De acordo com os resultados obtidos, os métodos de dosagem empregados se mostraram eficientes na obtenção da resistência requerida (25 MPa aos 28 dias de idade) para os traços controle e com adição de resíduo, classificando os concretos como estruturais. Para os traços com adição de resíduos, fica evidente que o aumento de 5,3\% no consumo de cimento e a 
utilização de aditivos superplastificantes influenciou diretamente no ganho de resistência das amostras.

Verificou-se também, entre 7 e 28 dias, um ganho de resistência próximo para os concretos controle e com adição de resíduos.

\subsection{RESISTÊNCIA À TRAÇÃO POR COMPRESSÃO DIAMETRAL}

A Figura 6 abaixo mostra os resultados de Resistência à Tração por Compressão Diametral dos Corpos de Prova controle e constituídos de resíduos de borracha de pneu, aos 7 e 28 dias de cura.

Figura 6: Resultados de Resistência à Tração por Compressão Diametral dos corpos de prova com e sem resíduo de borracha de pneu aos 7 e 28 dias de cura

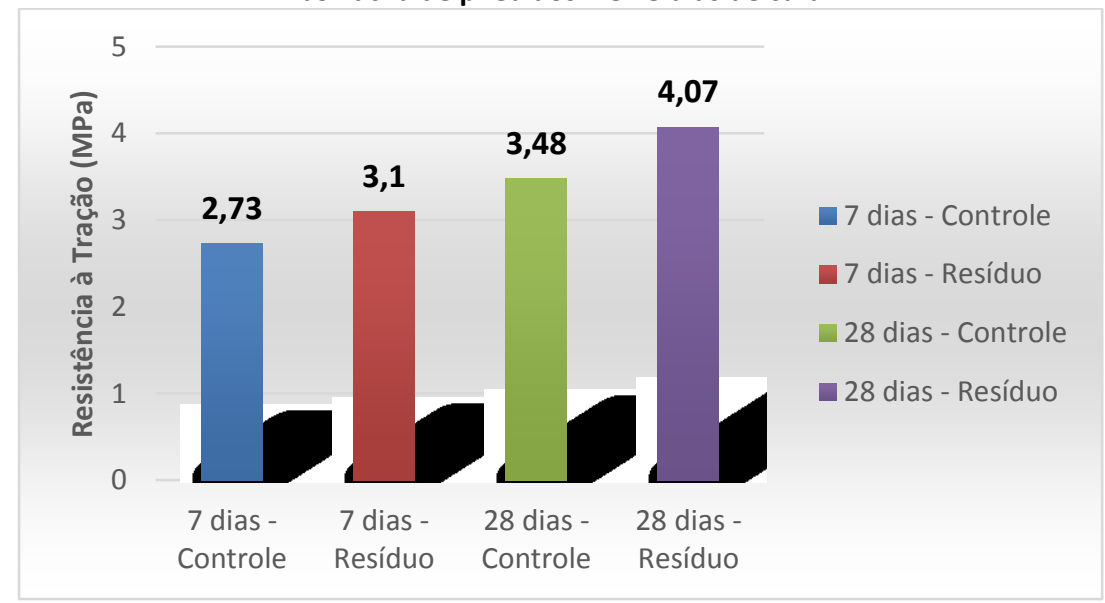

Fonte: ELABORADO PELOS AUTORES, 2016

Para a utilização estrutural, o concreto sozinho não é adequado como elemento resistente, pois enquanto tem uma boa resistência à compressão, pouco resiste à tração, sendo esta da ordem de $1 / 10$ daquela (CARVALHO E FIGUEIREDO, 2004).

Para aumentar a resistência do elemento estrutural, é importante a associação do concreto com um material que tenha boa resistência à tração e que seja mais deformável. O material utilizado mais comum é o aço, nas quais deve ser colocado longitudinalmente na região tracionada da peça. Tal associação pode ser denominada de Concreto Armado.

Neste aspecto, a inserção do resíduo de borracha de pneu se mostrou um material adequado para ser utilizado como agregado em concretos estruturais, visto que este proporcionou um aumento de aproximadamente $17 \%$ nos valores de resistência à tração aos 28 dias de cura. Tal propriedade pode se mostrar interessante na elaboração de elementos estruturais constituídos de borracha de pneu, nas quais poderá absorver uma parcela dos esforços de tração juntamente com o aço.

\subsection{MÓDULO DE ELASTICIDADE}

A Figura 7 abaixo mostra os resultados de Módulo de Elasticidade dos Corpos de Prova controle e constituídos de resíduos de borracha de pneu, aos 7 e 28 dias de cura. 
Figura 7: Resultados de Módulo de Elasticidade dos corpos de prova com e sem resíduo de borracha de pneu aos 7 e 28 dias de cura

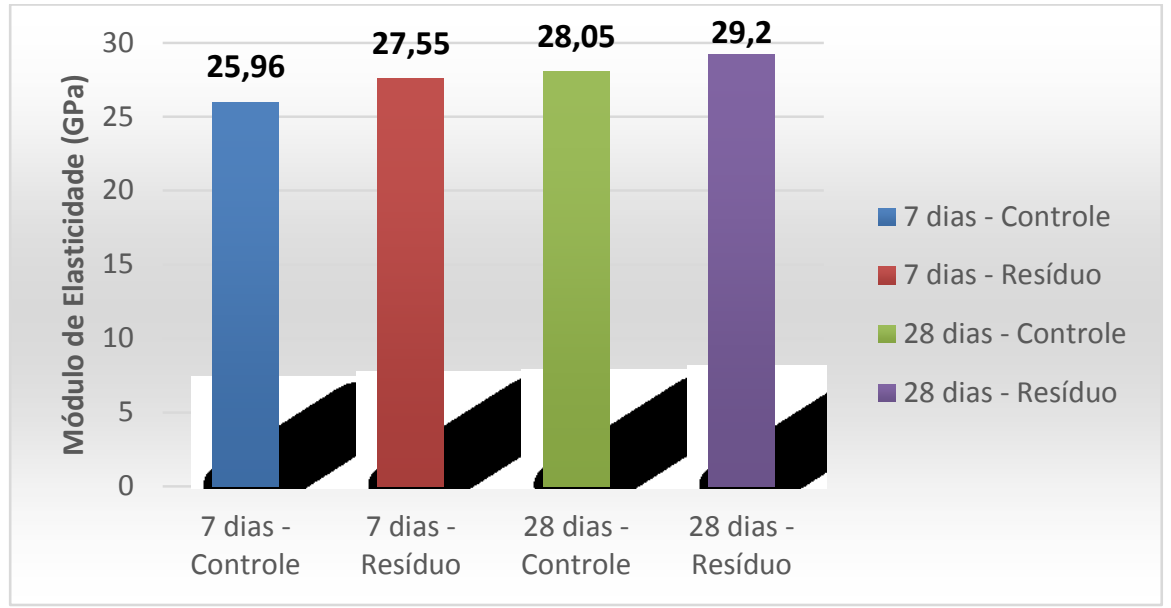

Fonte: ELABORADO PELOS AUTORES, 2016

Os dados obtidos mostram que o que concreto com adição de resíduo apresentou o valor do módulo de elasticidade ligeiramente maior que o módulo do concreto sem resíduo, tanto para os 7 quanto para os 28 dias de cura. De fato, apesar dos trabalhos mostrarem que a borracha proporciona uma queda dos valores de módulo de elasticidade, o aumento dos valores de resistência à compressão refletiu no ligeiro aumento dos valores desta propriedade.

Além disso, segundo Hartmann e Helene (2003), os aditivos químicos e a relação água/cimento têm influência direta no módulo de elasticidade dos concretos. Menores relações água/cimento, para resistências constantes, indicam incrementos nos módulos de elasticidade. Assim como observado neste trabalho para os traços com resíduo, os autores verificaram que, para resistências constantes, o uso de superplastificantes requereu relações água/cimento mais baixas e consequentemente módulos de elasticidade maiores, quando comparados ao concreto referência.

\subsection{ABSORÇÃO DE ÁGUA}

A Figura 8 abaixo mostra os resultados de Absorção de Água dos Corpos de Prova controle e constituídos de resíduos de borracha de pneu, aos 28 dias de cura. 
Figura 8: Resultados de Absorção de Água dos corpos de prova com e sem resíduo de borracha de pneu aos 28 dias de cura

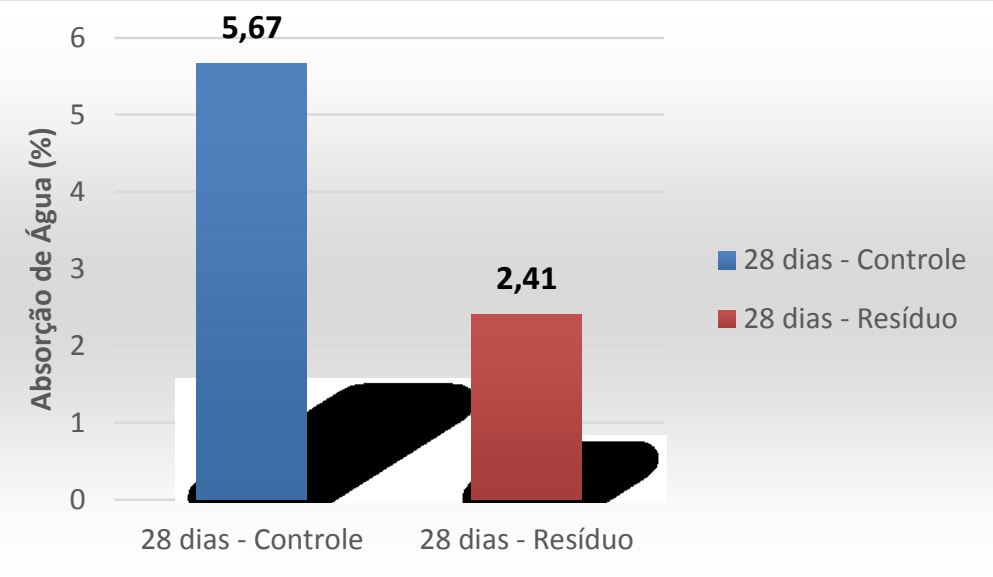

Fonte: ELABORADO PELOS AUTORES, 2016

Os dados mostram claramente que a inclusão da borracha nos concretos causa redução da absorção de água. Todos os corpos de prova controle apresentaram valores de absorção superiores aos traços com resíduo, sendo a redução de aproximadamente $53,7 \%$ para os traços com resíduo, em relação aos traços controle. Em função da borracha atuar como poros fechados no interior dos concretos, já que sua taxa de absorção é nula, a adição de resíduos de borracha de pneu em concretos pode servir como uma forma de aumentar a sua durabilidade.

\subsection{MASSA ESPECÍFICA}

A Figura 9 abaixo mostra os resultados de Massa Específica dos Corpos de Prova controle e constituídos de resíduos de borracha de pneu.

Figura 9: Resultados de Massa Específica dos corpos de prova com e sem resíduo de borracha de pneu

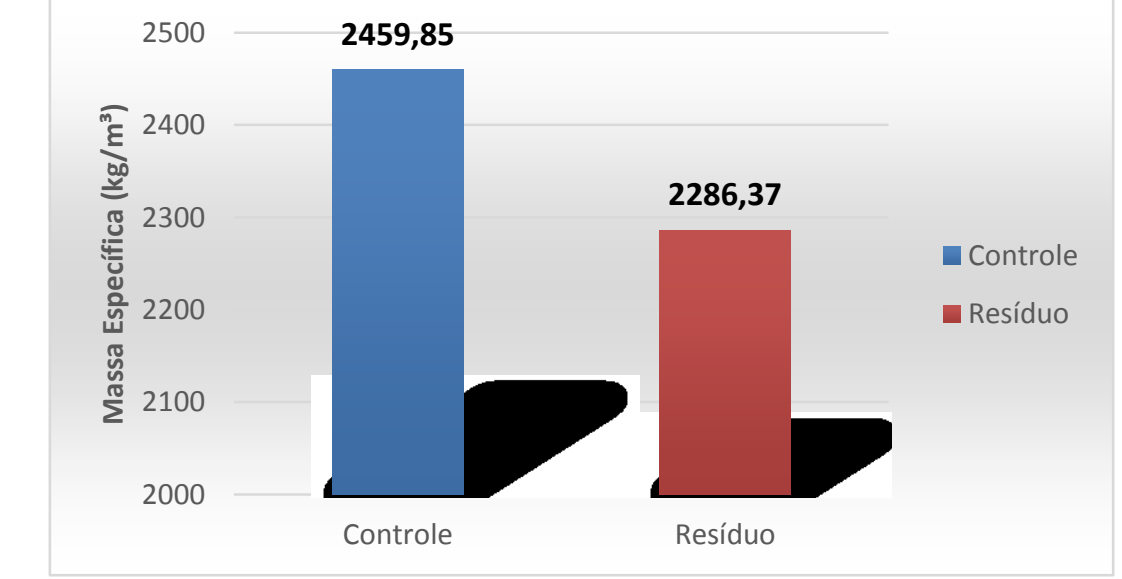

Fonte: ELABORADO PELOS AUTORES, 2016

Considerando a baixa massa específica da borracha em relação aos demais materiais empregados na elaboração dos traços (cimento, areia e brita), foi observada uma queda de $10,4 \%$ nos valores de massa específica das misturas de concreto constituídas de resíduo, em relação aos traços controle. 
As reduções constatadas são um indicativo que a adição de borracha pode reduzir do peso próprio das estruturas e consequentemente reduzir os custos com fundações.

\subsection{TEOR DE AR INCORPORADO}

A Figura 10 abaixo mostra os resultados de Teor de Ar Incorporado dos Corpos de Prova controle e constituídos de resíduos de borracha de pneu.

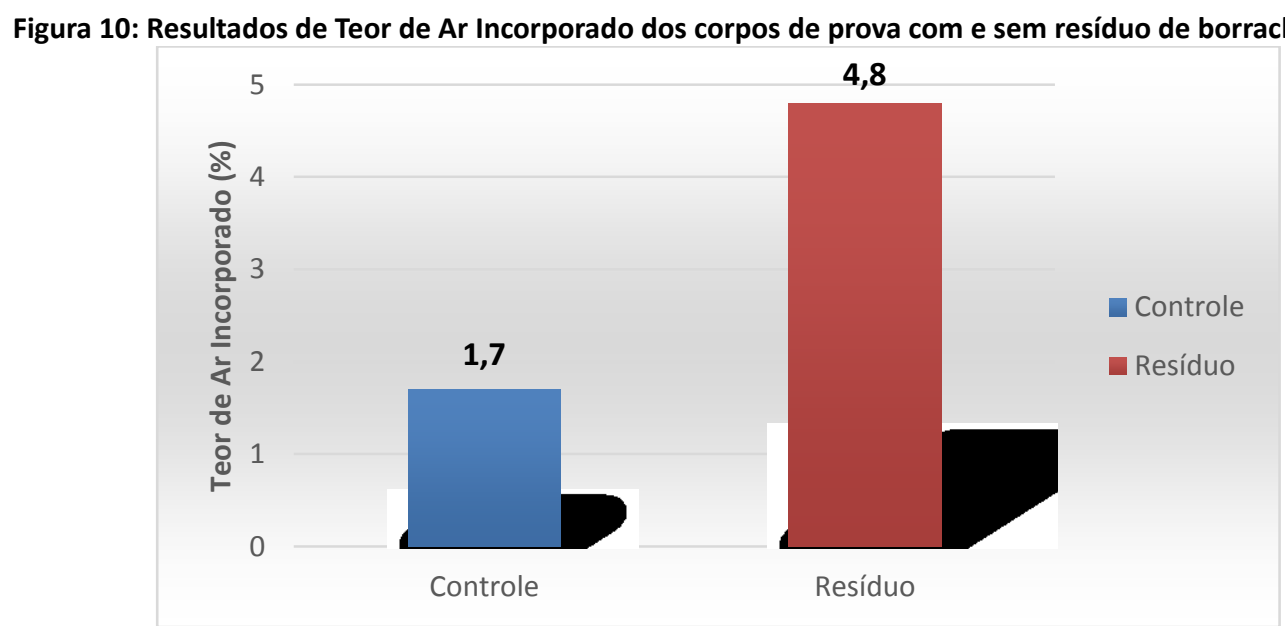

Fonte: ELABORADO PELOS AUTORES, 2016

Constatou-se que os traços com resíduo de borracha apresentaram aumento nos valores de teor de ar incorporado, se comparado aos traços sem resíduo. Considerando que o formato alongado (tipo fibra) do resíduo tem influência na capacidade de reter ar no interior das misturas, decidiu-se, neste trabalho, adicionar os resíduos de borracha no final das misturas em betoneira, de forma a reduzir a diferença entre os traços sem e com adição de borracha.

Entretanto, o aumento do teor de ar incorporado não refletiu no aumento da absorção de água das misturas, na qual a capacidade da borracha não absorver água teve maior influência do que $o$ aumento de poros nas misturas.

\section{CONCLUSÃO}

A aplicação de resíduos de borracha de pneu triturado na indústria da construção civil tem se mostrado promissora, na necessidade de se preservar o meio ambiente e de garantir o prolongamento das reservas naturais, que fornecem matérias-prima necessárias para a elaboração dos concretos.

Neste contexto, o trabalho objetivou a utilização de resíduos de borracha em substituição parcial dos agregados do concreto para a obtenção de concretos estruturais.

De acordo com os resultados obtidos, os métodos de dosagem empregados se mostraram eficientes na obtenção da resistência mínima requerida para os traços sem e com adição de resíduo. Para obtenção da mesma resistência de projeto requerida, foi constatado um acréscimo no consumo de cimento para o concreto emborrachado, ficando evidente que que o aumento no consumo de cimento e a utilização de aditivos superplastificantes influenciou diretamente no ganho de resistência das amostras.

A inserção do resíduo de borracha de pneu se mostrou um material adequado para ser utilizado como agregado em concretos estruturais, visto que este proporcionou um aumento 
nos valores de resistência à tração aos 28 dias de cura, superior à ordem de $10 \%$ dos valores médios de resistência à compressão axial. Tal propriedade pode se mostrar interessante na elaboração de elementos estruturais constituídos de borracha de pneu, nas quais poderá absorver uma parcela dos esforços de tração juntamente com o aço.

Os dados obtidos mostram que o que concreto com adição de resíduo apresentou o valor do módulo de elasticidade ligeiramente maior que o módulo do concreto sem resíduo. De fato, apesar dos trabalhos mostrarem que a borracha proporciona uma queda dos valores de módulo de elasticidade, o aumento dos valores de resistência à compressão refletiu no ligeiro aumento dos valores de módulo, considerando a utilização de aditivos superplastificantes e a redução do fator água/cimento para tais misturas.

A adição de resíduos nos concretos causa redução nos valores de absorção de água. Em função da borracha atuar como poros fechados no interior dos concretos, já que sua taxa de absorção é nula, a adição de borracha de pneu em concretos pode servir como uma forma de aumentar a sua durabilidade.

Os dados mostraram que a baixa massa específica da borracha refletiu na redução dos valores de massa específica das misturas de concreto constituídas de resíduo, em relação aos traços controle. Isso pode ser um indicativo que a adição de borracha pode reduzir do peso próprio das estruturas e consequentemente reduzir os custos com fundações.

Em função do formato alongado (tipo fibra) do resíduo, as misturas apresentaram um aumento nos valores de teor de ar incorporado, se comparado aos traços sem resíduo, apesar da absorção de água das amostras com resíduo ser inferior às amostras controle.

A análise geral dos resultados obtidos mostra que a inserção de resíduo de borracha de pneu em misturas de concreto estruturais pode proporcionar diversas vantagens técnicas em relação aos concretos convencionais. $\mathrm{O}$ trabalho mostra que, para pequenas alterações na composição das misturas, é possível se produzir concretos estruturais, substituindo-se os agregados por fibras de borracha, mostrando ser uma alternativa que vem garantir a sustentabilidade do planeta e a preservação dos recursos naturais.

\section{REFERÊNCIAS BIBLIOGRÁFICAS}

ASSOCIAÇÃO BRASILEIRA DE NORMAS TÉCNICAS - ABNT. NBR 5738: concreto - procedimento para moldagem e cura de corpos-de-prova. Rio de Janeiro, 2008. 6 p.

ASSOCIAÇÃO BRASILEIRA DE NORMAS TÉCNICAS - ABNT. NBR 5739: concreto - ensaio de compressão de corpos-deprova cilíndricos concreto. Rio de Janeiro, 2007. 9 p.

ASSOCIAÇÃO BRASILEIRA DE NORMAS TÉCNICAS - ABNT. NBR 6118: projeto de estruturas de concreto procedimento. Rio de Janeiro, 2014.

ASSOCIAÇÃO BRASILEIRA DE NORMAS TÉCNICAS. NBR 7215: cimento portland - determinação da resistência à compressão. Rio de Janeiro, 1997. 8 p.

ASSOCIAÇÃO BRASILEIRA DE NORMAS TÉCNICAS - ABNT. NBR 7222: argamassa e concreto - determinação da resistência à tração por compressão diametral de corpos-de-prova cilíndricos. Rio de Janeiro, 2011. 5 p.

ASSOCIAÇÃO BRASILEIRA DE NORMAS TÉCNICAS - ABNT. NBR 8522: concreto - determinação dos módulos estáticos de elasticidade e de deformação e da curva tensão-deformação. Rio de Janeiro, 2008. 16 p.

ASSOCIAÇÃO BRASILEIRA DE NORMAS TÉCNICAS. NBR 9778: argamassa e concreto endurecidos - determinação da absorção de água por imersão, índice de vazios e massa específica. Rio de Janeiro, 2009. 4 p. 
ASSOCIAÇÃO BRASILEIRA DE NORMAS TÉCNICAS - ABNT. NBRNM 47: concreto - determinação do teor de ar em concreto fresco - método pressométrico. Rio de Janeiro, 2002. 23 p.

ASSOCIAÇÃO BRASILEIRA DE NORMAS TÉCNICAS. NBRNM 67: concreto - determinação da consistência pelo abatimento o tronco de cone. Rio de Janeiro, 1998. 8 p.

ASSOCIAÇÃO NACIONAL DA INDÚSTRIA DE PNEUMÁTICOS - ANIP. Reciclanip apresenta balanço do primeiro trimestre de 2015. São Paulo: ANIP, 2015. Disponível em: < http://www.anip.com.br >. Acesso em: 13 jul. 2016.

CARVALHO, R. C.; FIGUEIREDO, J. R. F. Cálculo e Detalhamento de Estruturas Usuais de Concreto Armado: Segundo a NBR 6118:2003. 2. ed. São Carlos: EdUFSCar, 2004. 374 p.

HARTMANN, C. T.; HELENE, P. R. L. Avaliação de aditivos superplastificantes base policarboxilatos destinados a concretos de cimento Portland. São Paulo: EPUSP, Departamento de Engenharia de Construção Civil, 2003. 22p. (Boletim Técnico da Escola Politécnica da USP, BT/PCC/330).

HELENE, P.; TERZIAN, P. Manual de dosagem e controle do concreto. $1^{\circ}$ ed. São Paulo: PINI, 1993. 349 p.

HOLMES, Nail; DUNNE, Kevin; O'DONNELL, John. Longitudinal shear resistance of composite slabs containing crumb rubber in concrete toppings. Construction and Building Materials, v. 55, p. 365-378, 2014.

KAMIMURA, E. Potencial de utilização dos resíduos de borracha de pneus pela industria da construção civil. 2002. 127 f. Dissertação de Mestrado - Universidade Federal de Santa Catarina, Programa de Pós - Graduação em Engenharia Civil, Florianópolis, 2002.

LOPES, M. D.; MARQUES, A. C.; RICCI, E. C.; FIORITI, C. F.; AKASAKI, J. L. Estudo de Dosagens para Obter Concretos com Resíduos de Borracha de Pneu. In: CONGRESSO BRASILEIRO DO CONCRETO, 47, 2005, Recife. Anais... São Paulo: Ibracon, 2005.

MARQUeS, M. L.; MARQUES, A. C.; TRIGO, A. P. M.;AKASAKI, J. L. Avaliação do Comportamento da Argamassa Adicionada de Diferentes Granulometrias de Borracha após Tratamento Superficial. In: CONGRESSO BRASILEIRO DO CONCRETO, 47, 2005, Recife. Anais... São Paulo: Ibracon, 2005.

O’REILLY DÍAZ, VITERVO. Método de dosagem de concreto de elevado desempenho. São Paulo: Pini; Brasília, 1998. $122 \mathrm{p}$.

SIDDIQUE, R; NAIK, T. Properties of concrete containing scrap-tire rubber-an overview. Waste Manage;24:539-63.

SON, K. S.; HAJIRASOULIHA, I.; PILAKOUTAS, K. Strength and deformability of waste tyre rubber-filled reinforced concrete columns. Construction and Building Materials, v. 25, p. 218-226, 2011. 